\title{
SYMBOLIC PROCESSES IN ERP VERSUS LEGACY SYSTEM USAGE
}

\author{
Martin M. T. Ng \\ Michael T. K. Tan \\ National University of Singapore
}

\begin{abstract}
Being hailed as possessing the ability to drive effective business reengineering and management of core and support processes, it is not surprising that enterprise resource planning (ERP) systems have been adopted by more than 60 percent of Fortune 500 companies at the turn of the century. In contrast, legacy systems have frequently been attached with negative connotations. Yet at the same time, it is common knowledge that some legacy systems are not replaced when companies adopt ERP solutions, while new in-house systems still continue to be developed. While risks and time involved have been highlighted as possible reasons for the non-replacement of legacy systems, little attention has been paid to process issues as well as the symbolic meanings attached to the ERP vis-à-vis the other coexisting information systems.

This research employs symbolic interactionism as the informing theoretical perspective in an ethnographic study of a large government authority in Singapore. Our findings surprisingly indicate that contrary to popular belief, the end-users in that organization tend to attach rather favorable symbols to their legacy and new in-house developed systems, while displaying relatively negative sentiments towards their ERP package. In this paper, we first discuss the different symbolism attached over the years to the coexisting systems. Next, we highlight how certain symbols gradually got sedimented over time. Finally, we demonstrate how the consequent manifestations of these symbolic realities influenced certain organizational actions that impacted the usage and perpetuation of the coexisting systems.
\end{abstract}

Keywords: Symbolic interactionism, symbolism, enterprise resource planning (ERP), legacy system 


\section{INTRODUCTION}

By 2000, more than 60 percent of Fortune 500 companies had adopted ERP packages and this is a trend that is increasingly being followed by small- and medium-sized enterprises (SMEs) as they realize the cost effectiveness and competitive necessity to follow suit (Klaus et al. 2000). In contrast, legacy systems have been described as having a "consequentially negative impact on competitiveness" in that they tend to "resist modification and evolution to meet business requirements" (Brodie and Stonebraker 1995) while being "non-maintainable and inflexible" (O'Callaghan 1999). In fact, during the implementation process of ERP packages, legacy systems have sometimes been constructed by the organization to assume the identity of a "dying system" in order to facilitate the transition (Alvarez 2000). However, it is a well-known fact that some legacy systems are not replaced when companies adopt ERP solutions (Themistocleous and Irani 2001), while new in-house systems still continue to be developed.

In this study, we adopt symbolic interactionism as the informing theoretical perspective as it may help to shed new light on the difference in attitudes toward such coexisting systems. Besides being underutilized in IS research, this perspective is particularly appropriate in this study as little attention has been paid in extant ERP literature to process issues (Markus and Tanis 2000) as well as the symbolic meanings attached to the ERP vis-à-vis the legacy and new in-house developed systems.

\section{ERP VERSUS LEGACY SYSTEMS REVISITED}

Over the years, firms have been trying to replace legacy systems built on outdated technologies, based on the potential benefits and promises of standardization offered by the more powerful and comprehensive ERP package (Ross and Vitale 2000).

However, Themistocleous and Irani (2001) recently argued that ERP packages have in fact failed to achieve application integration and 38 percent of companies who adopt these ERP solutions do not replace their legacy systems. Specifically, ERP packages do not seem to be able to "cover all the business processes of an enterprise" and, as such, organizations typically do not "abandon all their existing applications when adopting ERP solutions" (Schönefeld and Vering 2000). Indeed, there is an increasing recognition of the need for legacy systems to persist in the organization in varying degrees and, toward that end, generic IS design strategies have been offered for effective coexistence of ERP and legacy systems within organizations (Holland and Light 1999).

\subsection{Symbolism at Work?}

In information systems development work, it has been noted that "myth, magic and metaphor" are often employed (Hirschheim and Newman 1991). Similarly, many ERP implementations are often associated with a "mythmaking" process whereby the incoming ERP package is usually slated to be the "ideal system" while the outgoing legacy systems are usually attached with the title of a "dying system" (Alvarez 2000). Clearly, there may be much symbolism at work in the implementation and use of ERP systems within organizations. Gaining an appreciation of such symbolism may, therefore, yield new and interesting insights in this ERP arena. 


\subsection{Symbolic Interactionism as a Theoretical Perspective}

Together with phenomenology and hermeneutics, symbolic interactionism is one of several prominent interpretive approaches to social science research. The central idea of symbolic interactionism is that humans attach meanings to objects during the course of everyday social interaction with others. In this regard, there has been increasing interest over the years in the role of symbolism within organizations in general (Turner 1990) and of the symbolic nature of computers and IT in particular (Prasad 1993). In IS literature, prominent researchers have also similarly recognized the importance of symbolism when organizational and technological contexts intersect (e.g., Hirschheim and Newman 1991). However, there have been few noteworthy studies in IS literature that have explicitly used symbolic interactionism as a theoretical perspective.

In this regard, symbolic interactionism is particularly appropriate in this study because it "simultaneously emphasizes both process issues and the roles ofmeaning and symbols" (Prasad 1993). Consideration of process issues is important to facilitate understanding of how the symbols and meanings attached by end-users to the coexisting information systems (i.e., ERP vis-à-vis legacy and new in-house developed systems) come to be sedimented over time.

\section{CASE DESCRIPTION}

This research takes place in a large government authority (the Authority) in Singapore. Having begun operations in the early 1970s, the Authority has since grown to a strength of 10 divisions, employing approximately 2,000 people and establishing itself as a major global hub in the transportation industry. The sequence of events and the corresponding implications impacting the coexisting information systems are best represented on a timeline, elaborated in Figure 1.

\section{RESEARCH METHODS}

This research uses symbolic interactionism as the theoretical perspective to inform an ethnography study in which the first author was immersed in day-to-day activities at the Authority for almost three months in early 2003. During this period, he worked in the Information Systems (IS) department, whose function is to oversee project implementation of back-end systems (including the ERP package) and to ensure the smooth daily operations of these systems. Being attached to the IS department allowed the author to interact with end-users and management by following the support staffas they went on-site to solve day-to-day problems. Data collection consisted of observation, participant-observation, and interviews (Prus 1996) including informal chats and document reviews. Ethnographic notes were recorded and reflected upon contemporaneously (at the end of each day) as much as possible. The subsequent few months were spent off-site but regular contact was maintained in order to clarify and verify the findings, as the written ethnographic account took shape. 


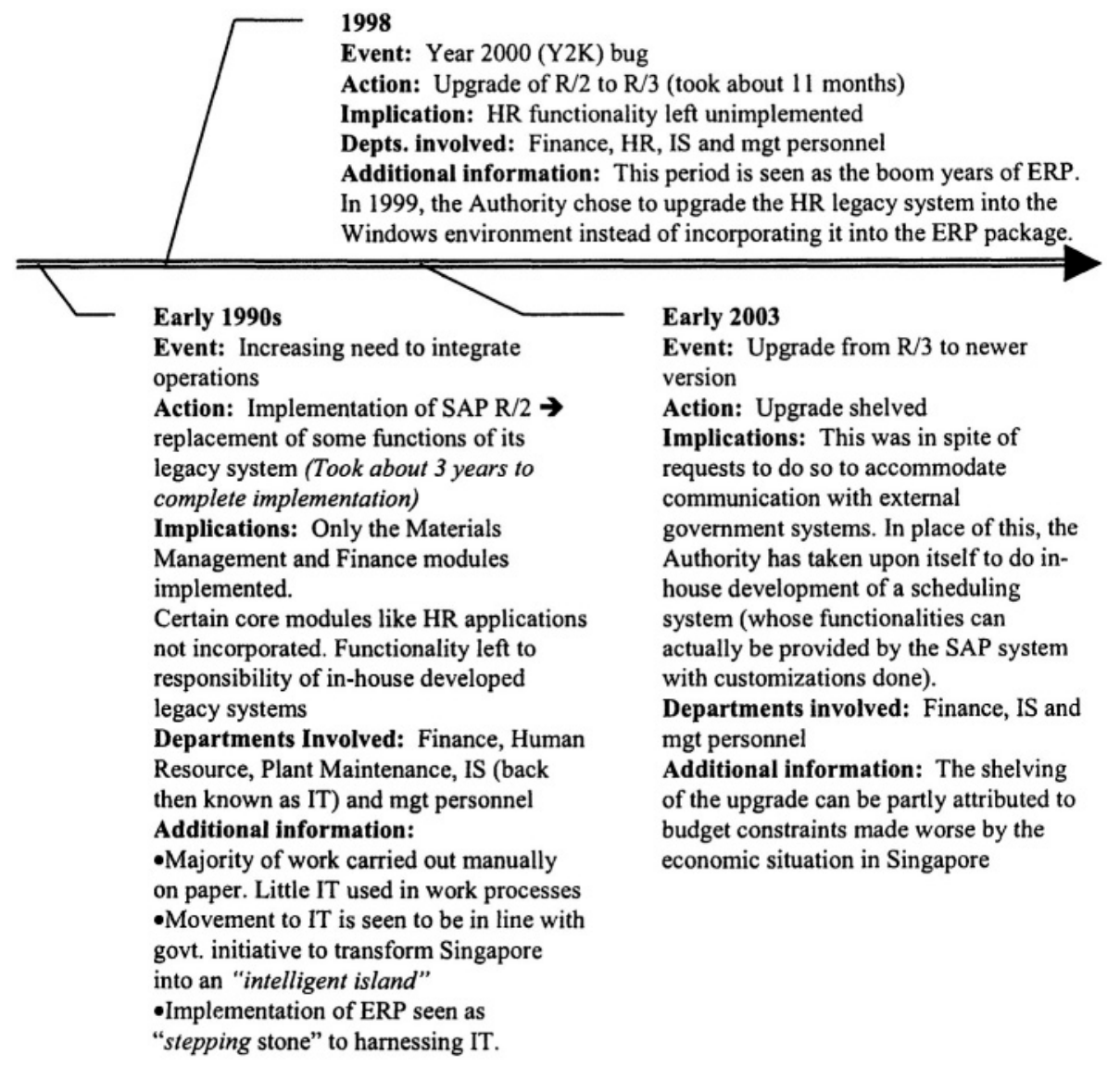

Figure 1. Timeline of Events

\section{RESEARCH FINDINGS}

\subsection{Multiple Symbolic Representations}

To begin, it is important to note that the multiple symbols attached to the ERP package vis-a-vis the legacy and new in-house developed systems (as tabulated in Table 1) are the more prominent ones to emerge from this study.

Together, these seven different symbolic realities serve to paint a clearer picture of the end-users' perspectives of the coexisting systems. Clearly, the end-users do not seem to attach any negative symbols to their legacy and new in-house systems while doing so for the ERP package. Another point worth noting is that in spite of the transition from the mainframe-based R/2 system to the client-server R/3 system, there seems to be an improvement in the status of the legacy system relative to the ERP package: some of the 
positive symbolism attached to the latter gradually eroded while much of negative symbolism gradually sedimented over time.

\subsection{Temporal and Local Meanings of Symbolic Representations}

As per Table 1, this study shows that not only do the end-users attach different symbols to the coexisting information systems but that they also interpret the various symbols in different ways (e.g., efficiency means better use of resources to some, while others perceive it as integration). As noted by Prasad (1993), a focus on local meanings is important to symbolic interactionists.

We also observe that beyond local meanings, some symbols signify different meanings at different times (e.g.,potential). Close examination of these temporal and local meanings reveals that the end-users have, over time, developed an increasingly negative sentiment toward the ERP package.

\subsection{Sedimentation of Symbols}

The study of the sedimentation process of the symbols is as important as, if not more than, the identification of the symbols themselves and their local/ temporal meanings. This focus is supported by theorists like Fine (1992) who argue that attention should be directed to the forces behind the sedimentation.

At any one time, there are multiple symbols attached to the systems but only those that exhibit a degree of persistence and presence will develop into organizational realities. Certain symbols exhibit a strong presence within a given time frame, but fail to persist as the system undergoes a transition.

In the case of the Authority, we argue that there were three main forces that proved to be instrumental in determining the persistence and presence of the various symbols (as tabulated in Table 1). They are

- Management influence: Impact on misalignment and uncontrollable

- Innovation fit: Impact on efficiency, potential, and exclusivity

- Interaction with system: Impact on uncontrollable, efficiency, potential, exclusivity and intuitive

\subsection{Symbolic Manifestation and Impact}

As noted by Prasad (1993), the "process of enactment, whereby symbolic realities mediate meaningful action" is a central concern of any research project for symbolic interactionists. It was apparent that the evolving symbolism resulted in

- Erosion of support for the proposed upgrade of the ERP package in early 2003

- Resistance to the incoming human resources component of the ERP package during the initial R/2 implementation in the early 1990s

- Inadequate use of the ERP package over time 


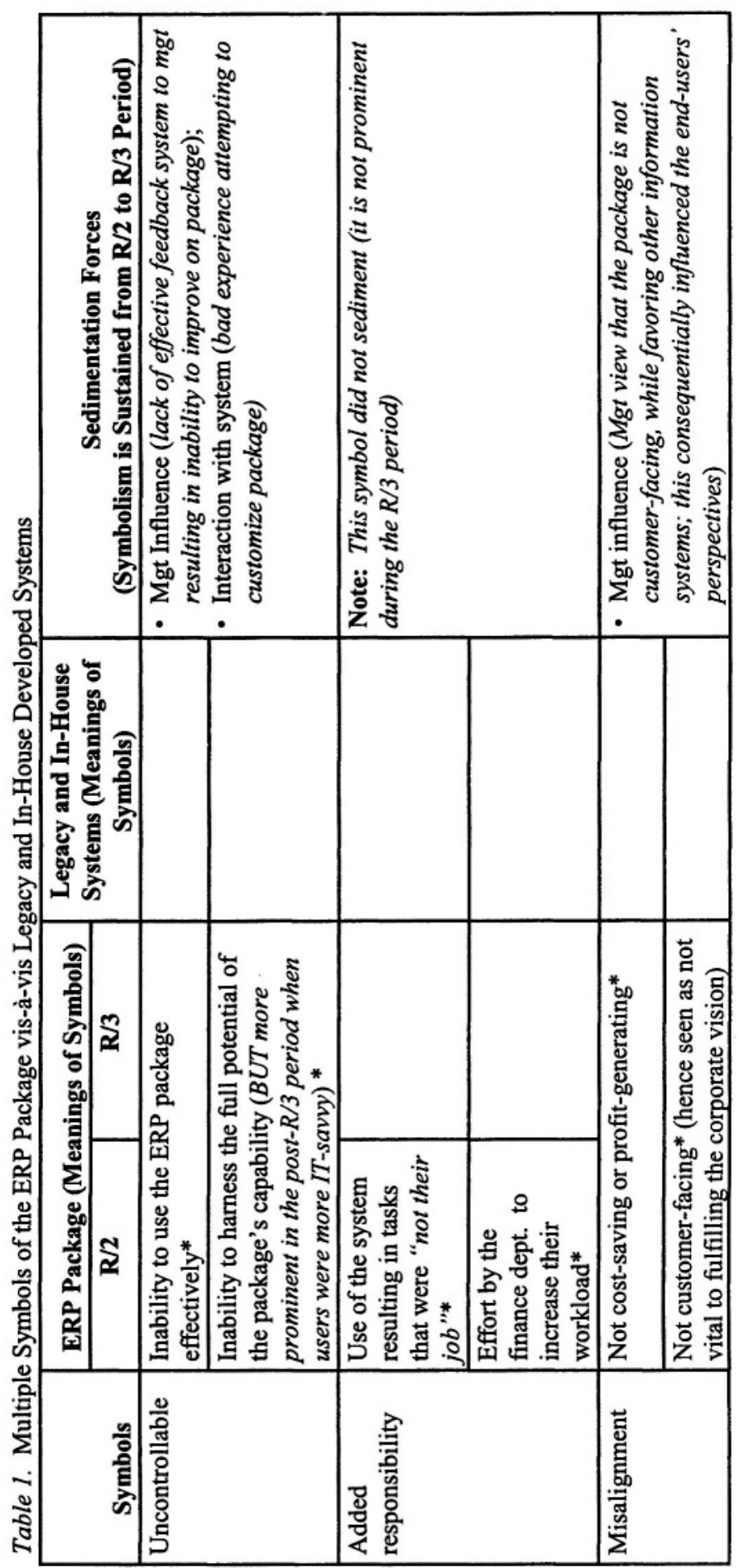




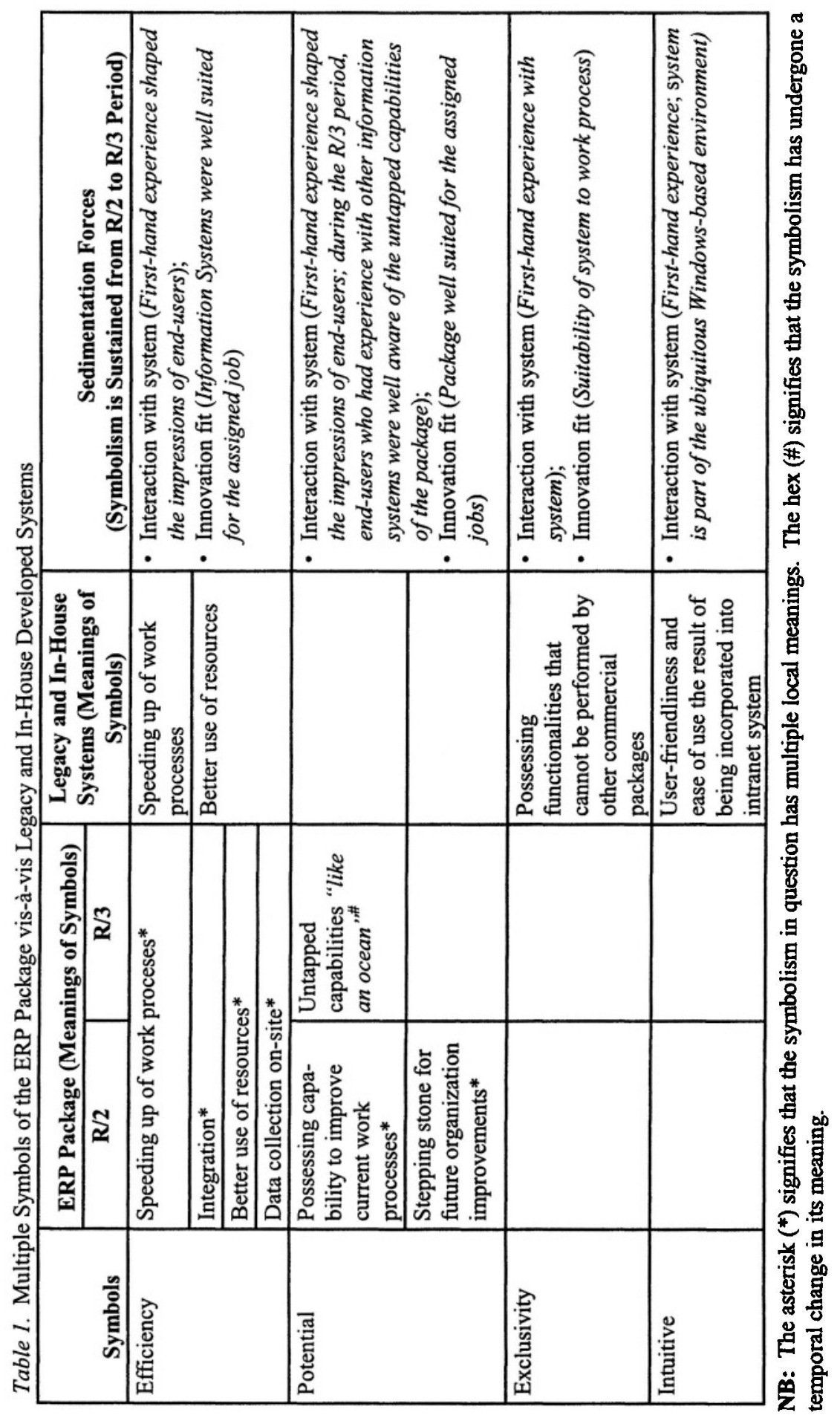


Together, these manifestations give an idea as to why certain core modules like the human resources application were left out during the initial R/2 implementation and subsequent $R / 3$ upgrade. They also shed light on why during early 2003 , end-users readily accepted management's decision to shelve the SAP upgrade without much opposition, in spite of the fact that it resulted in extra in-house development work (to accommodate electronic communication with external government systems). As noted by Lindesmith (1981), "a cause must be thought of as a process—not as a condition...or event" and in the same vein, one must recognize that there are many other events working with the identified manifestations (which only constitute part of the cause of the actions taken by the Authority). At the IFIP Working Conference in Manchester, we will elaborate on this important issue.

\section{DISCUSSION}

As Prasad (1993) recognized in his employment of symbolic interactionism, theoretical insights offered are more like guiding propositions than testable hypotheses. As such, the findings emerging from this study may not be universally applicable statements, but they offer several empirically supported perspectives that aid in the understanding of the coexistence of the ERP package vis-à-vis the legacy and new inhouse developed systems.

\subsection{Relative Position of Systems over Time}

Although IS literature has recognized the negative connotations usually attached to the outgoing legacy systems, this study finds that this representation may not be always accurate. In the case of the Authority, end-users instead view their legacy and new inhouse systems more favorably than the commercially developed ERP package.

Specifically, this study suggests that the relative positions of coexisting systems may be the result of a combination of processes resulting in the sedimentation of various symbolic realities within the organization. For example, sedimentation forces such as management influence and technological fit have been frequently highlighted as important implementation success factors (e.g., Meyers et al. 1999). This study demonstrates that beyond the implementation phase, these same forces may also be important factors to consider in the maintenance and upgrade phases of information systems.

\subsection{Perpetuation and Usage of Systems over Time}

In this regard, ERP maintenance and upgrade decisions are frequently attributed in the literature to such fundamental factors as maintenance costs, availability of new versions, and benefit-realization (e.g., See 2001). However, this study suggests that the symbolism attached to the ERP system by the end-users may also be critical. This is in line with Feldman (1989), who notes that all too often, the technical aspects are focused on when considering technological change processes, while the equally important symbolic aspects are neglected. In fact, Feldman and March (1981) suggest that "information technologies are used and introduced primarily for their symbolic value." 
Similarly for legacy systems, we suggest that their varying degrees of persistence may not always be a result of the time needed and the risks involved, but could be due to the organizational impact of the symbolic representations attached to them.

\section{CONCLUSION}

In this study, the combination of leveraging the theoretical strengths of symbolic interactionism (as a cognitive lens) and the empirical strengths of ethnography (as the strategy of inquiry) has allowed for a unique comparison of the relative positions of the ERP package vis-à-vis legacy and new in-house developed systems within a particular organization.

Our key message is that the symbolic representations attached to these systems may thus have strong implications on their perpetuation and usage. Another important point highlighted by this study is the influence of various forces on the sedimentation of such symbolic realities within the organization. The identification of such forces may serve as a valuable guideline to IS practitioners in their attempts to influence the perpetuation and use of various information systems within the organization.

In closing, through its choice of symbolic interactionism as the cognitive lens, this study points to the importance of employing different theoretical perspectives (such as critical social theory, actor network theory, and structuration theory) to examine the ERP phenomenon. Indeed, we suggest that when such complementary perspectives are purposefully employed in a portfolio of separate studies over time, they may collectively help to shed new light on the complexities of ERP implementations in organizations.

\section{REFERENCES}

Alvarez, R. "Examining an ERP Implementation through Myths: A Case Study of a Large Public Organization," in H. M. Chung (Ed.), Proceedings of the Sixth Americas Conference of Information Systems 2000, Long Beach, CA, 2000, pp. 1655-1661.

Brodie, M., and Stonebraker, M. Migrating Legacy System, San Francisco: Morgan Kaufmann Publishers, 1995.

Feldman, S. P. "The Idealization of Technology: Power Relations in an Engineering Department," Human Relations (42), 1989, pp. 575-592.

Feldman, M. B., and March, J. G. "Information in Organizations as Signal and Symbol," Administrative Science Quarterly (26:2), 1981, pp. 171-186.

Fine, G. A. "Agency, Structure and Comparative Contexts: Towards a Synthetic Interactionism," Symbolic Interaction (15:1), 1992, pp. 87-107.

Hirschheim, R., and Newman, M. "Symbolism and Information Systems Development: Myth, Metaphor and Magic," Information Systems Research (2:1), 1991, pp. 29-62.

Holland, C. P., and Light, B. "Generic Information Systems Design Strategies," in W. D. Haseman and D. L. Nazareth, Proceedings of the Fifth Americas Conference on Information Systems, Milwaukee, WI, 1999, pp. 396-398.

Klaus, H., Rosemann, M., and Gable, G. G. "What is ERP?," Information Systems Frontiers (2:2), 2000, pp. 141-162.

Lindesmith, A. R. "Symbolic Interactionism and Causality," Symbolic Interaction (4:1), 1981, pp. 87-96. 
Markus, M. L, and Tanis, C. "The Enterprise System Experience-From Adoption to Success," in R. W. Zmud (Ed.), Framing the Domains of IT Management: Projecting the Future through the Past,Cincinnati,OH: PinnaFlex Educational Resources, Inc., 2000, pp. 173207.

Meyers, P. W., Sivakumar, K., and Nakata, C. "Implementation of Industrial Process Innovations: Factors, Effects and Marketing,' Journal of Product Innovation Management (16:3), 1999, pp. 295-311.

O' Callaghan, A “Migrating Large Scale Legacy Systems to Component-Based and Object Technology,“ Communications of the Associationfor Information Systems (2:3), 1999.

Prasad, P. "Symbolic Processes in the Implementation of Technological Change: A Symbolic Interactionist Study of Work Computerization," Academy of Management Journal (36:6), 1993, pp. 1400-1429.

Prus, R. Symbolic Interaction and Ethnographic Research, Albany, NY: State University of NewYork Press, 1996.

Ross, J. W., and Vitale, M. R. "The ERP Revolution: Surviving vs. Thriving," Information Systems Frontier (2:2), 2000, pp. 233-241.

Schönefeld, M., and Vering, O. "Enhancing ERP-Efficiency through Workflow-Services," in

H. M. Chung (Ed.), Proceedings of Sixth Americas Conference on Information Systems, Long Beach, CA, 2000, pp. 640-645.

See, C. P. N. "A Framework for Enterprise Resource Planning Maintenance and Upgrade Decisions," in D. Strong and D. Straub (Eds.), Proceedings of Seventh Americas Conference on Information Systems, Boston, MA, 2001, pp. 1026-1029

Themistocleous, M., and Irani, Z. "Benchmarking the Benefits and Barriers of Application Integration," Benchmarking (8:4), 2001, 317-331.

Turner, B. A. (Ed.). Organizational Symbolism, Berlin: Walter de Gruyter, 1990.

\section{ABOUT THE AUTHORS}

Martin M. T. Ng is an honors year undergraduate in the School of Computing at the National University of Singapore (NUS). Currently on a scholarship from a government authority in Singapore, he will join the industry in mid-2004. Martin can be reached at ngmongth@yahoo.com.sg.

Michael T. K. Tan is a doctoral candidate in the School of Computing at the National University of Singapore (NUS). He received his B.Sc. and M.Sc. degrees in computer science from this same university. Prior to commencing his doctoral studies, Michael accumulated practical experience in industry including stints as Information Systems Manager and Regional Industry Consultant (ERP). His research focuses on interorganizational systems, enterprise systems, strategic use of IT, management of IS and qualitative research methodologies. Michael can be reached at mtan@comp.nus.edu.sg. 